\title{
Timing and Synchronization of the Breeding Period in Pilumnus vespertilio (Crustacea: Pilumnidae) in Subtropical Okinawa, Japan ${ }^{1}$
}

\author{
Foel Kyomo Sr. ${ }^{2}$
}

\begin{abstract}
Observations on the temporal occurrence of copulating pairs, ovigerous females, monthly brooding periods, and embryo development stages in Pilumnus vespertilio Fabricius were carried out in the wild on Okinawa Island, Japan. The relationship between the female gonad and hepatopancreas during a reproductive period was also studied. These reproductive activities were observed in relation to the lunar cycles. An inverse relationship between mass of the hepatopancreas and development of the gonad was observed. Mating and breeding activities were perfectly synchronized with the lunar periodicity. Five broods from May to September were observed in a single breeding period, and the average brooding period was 21.2 days with an interlude of $8.5 \pm 3.1$ days between broods/months. The shortest interlude was between May and June (4 days). A sixth brood that started in October was not followed to the end because it started with very few ovigerous females. Embryo development time in days decreased with each stage and averaged 5.3 days per stage. Copulating activity and appearance of ovigerous females during successive broods (months) were clearly synchronized with the lunar cycle. Although copulating frequency was highest after the full moon, nearly $100 \%$ of females were ovigerous around the new moon. All females of any one sample carried eggs of the same development stage. All females released their larvae 1-3 days before full moon, coinciding with a high tide. Larvae are probably released during this time as a survival strategy against predators such as planktivorous fish and against adverse intertidal conditions during other times.
\end{abstract}

IN GENERAL, BRACHYURAN breeding periodicity can vary considerably; the major controlling factors appear to be latitude, temperature, larval food availability, and intertidal zonation (Sastry 1983). The tendency is toward extended reproductive seasons and continuous reproduction with decreasing latitude in benthic shallow-water crustaceans. With increasing latitudes, breeding seasons

1 This work was supported by JSPS (Japan Society for the Promotion of Science). Manuscript accepted 28 November 2001.

2 University of the Ryukyus, Tropical Biosphere Research Center, 3422 Sesoko, Motobu-cho, Okinawa 9050227, Japan (fax: 81-980-47-4919; E-mail: jokyomo@ hotmail.com).

Pacific Science (2002), vol. 56, no. 3:317-328

(C) 2002 by University of Hawai'i Press

All rights reserved become more restricted to periods of higher water temperatures (Giese and Pearse 1974, Sastry 1983, Kyomo 1986). The effect of intertidal zonation on breeding periodicity has been shown in tropical brachyuran species Sesarma messa, S. smithi, and S. erytbrodactyla. These species do not breed all year round but for 3,3 , and 5 months of the year, respectively, and their reproductive strategies are related to their positions on the shore (Greenwood and Fielder 1988). Macrophthalmus grandidieri, a shallow-water tropical species, breeds continuously year-round, whereas various species of $\dot{U}_{c a}$ in the same area but of different zonation do not (Emmerson 1994). For one reason or another, most of the studies on brachyuran reproductive ecology have been reported on different species of only these families: Grapsidae (e.g., Hiatt 1948, Seiple 1979, Saigusa 1981, Kyomo 1986, Omori et al. 1997, Tsuchida and Watanabe 1997), Ocypodidae (e.g., Christy 1978, Zucker 1978, 
Wada 1981, Henmi and Kaneto 1989, Kosuge et al. 1994), Portunidae (e.g., Archambault et al. 1990, Norman and Jones 1993, Norman 1996), and Majidae (Tsuchida and Watanabe 1991).

Very few reproductive studies, however, have been done on species of the family Xanthidae; for example, Neopanope sayi (Swartz 1978, De Vries and Forward 1989), Panapeus berbstii and Eurypanopeus depressus (McDonald 1982), Leptodius exaratus (Watanabe et al. 1990), and Eriphia smithii (Tomikawa and Watanabe 1992). Knudsen (1960) described reproduction, life history, and larval ecology of four xanthids: Lopbopanopeus l. leucomanus, L. bellus diegensis, Paraxantbias taylori, and Cycloxanthops novemdentatus in California. Pilumnus vespertilio Fabricius was a member of this family until very recently (Kyomo 1999, 2001). Notwithstanding, none of these studies on xanthids has reported on the relationship between breeding activities and the lunar cycles.

The only reported studies on Pilumnus vespertilio (Pilumnidae) include its geographical distribution (Sakai 1976), larval development (Lim and Tan 1981), feeding patterns and food habits (Kyomo 1999), and reproductive behavior (Kyomo 2001). The distribution of $P$. vespertilio ranges widely from Japan, central Pacific to Australia and New Zealand, various areas of the Indian Ocean, and the east coast of Africa (Sakai 1976). In Japan, this species is found in various localities of Sagami Bay and Okinawa Island (Sakai 1976). Preliminary surveys for this study on Okinawa showed that the species is found mostly in the northern (Motobu) and central (Maeda Misaki) parts of the island.

Larval development stages of xanthids, including $P$. vespertilio, have been studied as early as 1928 (Lim and Tan 1981). However, there have been no studies on the reproductive biology of $P$. vespertilio. This study first focused on the breeding activities of $P$. vespertilio with regard to the relationship between gonad and hepatopancreas activities. It was necessary to include the information on gonad activity because this organ is the primary indicator for the initialization of egg bearing and reproduction in crabs, and es- sentially growth and development depends on the food resources stored in the hepatopancreas (Adiyodi 1969, Kyomo 1986, 1988, Omori et al. 1997). Second, the study demonstrated how the occurrence of copulating pairs, ovigerous females, and the brooding period is synchronized with lunar cycles. Synchronized spawning in reproductive females was examined in terms of spawning time, monthly numbers of females becoming ovigerous, brooding periods, and larval release times.

\section{MATERIALS AND METHODS}

\section{Study Sites}

This study was carried out on Okinawa Island $\left(26^{\circ} 38^{\prime} \mathrm{N}\right.$, between $127^{\circ} \mathrm{E}$ and $128^{\circ} 30^{\prime} \mathrm{E}$ ), Japan. Although the island has subtropical characteristics, it experiences all four seasons of a temperate climate. Two sites, Bise (10 $\mathrm{km}$ from Sesoko Research Center) and Maeda Misaki (53 km from the Research Center), were used for sampling. Both sites are coral reef flats covered by water at high tide and are fully exposed only during very low tides of $\leq 60 \mathrm{~m}$. The sites are also used as fishing and diving spots. Furthermore, at the Bise site two populations were studied, $1.5 \mathrm{~km}$ apart on the same stretch of reef. Preliminary surveys showed that $P$. vespertilio was distributed in patches ranging from two to four mature individuals per square meter. A mature female was defined as the smallest female carrying eggs at $15.0 \mathrm{~mm}$ carapace width (CW). A mature male was defined as the smallest individual of $16.0 \mathrm{~mm} \mathrm{CW}$ found in copula. Individuals are most active during the ebbing tide, and particularly when there is still pool water in the burrow neighborhood.

\section{Ovary and Hepatopancreas Activities}

Ten to 20 mature females, irrespective of their reproductive condition (i.e., ovigerous or nonovigerous), were sampled once during full moon and once during new moon during daytime low tides, every month from April to October 1999. The sampling was alternated 
between the Bise and Maeda sites. Specimens were stored on ice and taken to the laboratory as soon as sampling was completed. Individuals were measured for carapace width and dissected to remove the gonads and hepatopancreas. The organs and bodies were weighed after drying at $60^{\circ} \mathrm{C}$ for $48 \mathrm{hr}$. Dry gonad and hepatopancreas indexes were then calculated as ratios of the weight of these organs to the total dry body weight (organs inclusive) $\times 100$ for each individual. These indexes have been referred to as the gonadosomatic index and the hepatosomatic index (Kyomo 1986). A mean was then calculated to determine the index for the month, irrespective of the reproductive condition of the female. The population of $P$. vespertilio was too small to collect a good sample size for each reproductive condition during the year.

\section{Active Numbers, Coupling, and Ovigerous Females}

Obsevations and sampling were done during daytime low tides of $\leq 60 \mathrm{~m}$ within $2 \mathrm{hr}$ before the lowest tide mark, from April to September. All mature and active individuals were captured and counted from transects $200 \mathrm{~m}$ long and from the low tide water's edge to 35 $\mathrm{m}$ toward the reef center. An individual was regarded as active when its body was wholly emerged from the burrow/crevice irrespective of any movement. Gender and the condition of females were also determined. Copulating pairs in an embrace position were counted; individuals were turned to the ventral side of their body and their abdomen was lifted by forceps. An easily lifted and pliable abdomen, especially in males, shows that the male opens it for copulation. Otherwise, abdomens of uncopulated and particularly of immature males are held firmly to the sterna (Knudsen 1960). For escaping pairs, it was the female who entered the nearby burrow/crevice. The male was captured and the condition of the abdomen was checked. Seasonal changes in daily numbers of active individuals, copulating pairs, and ovigerous females were determined and related to the cycle of the moon. Successive observations and sampling were alternated between Bise and Maeda Misaki.

\section{Temporal Spawning and Brooding}

The determination of spawning dates and the number of brooding days needed to be done daily and this was done on the Bise populations only. Sampling at Maeda Misaki was stopped temporarily during the determination of the spawning dates. During spawning and brooding times, temperature of the air and pool water was noted. An intensive search for ovigerous females was done on every sampling day. A small sample was "pinched off" from the egg masses of 10 to 15 ovigerous females and their embryonic development stages were observed under a microscope. Development stages were modified from Henmi and Kaneto (1989) and categorized as follows. Stage $\mathrm{I}(\mathrm{a})$ : egg mass (orange) fully filled with a compartmentalized yolk, leaving no open space on the margins; stage I(b): compartments have disappeared but yolk appears as oil globules with $5-10 \%$ space on the margins of the egg mass; stage II: yolk looks like an assemblage of oil globules and is slightly pulled off the spherical margin, leaving $10-35 \%$ open space at one point or around the entire egg mass, and two dotlike red eyespots may be seen; stage III: two elliptical, light brown eyespots, surrounded by an orange color, and yolk is reduced to $\leq 50 \%$ of the egg mass; stage IV: two distinctive elliptical, dark brown eyespots, and developing blood vessels and abdomen may be seen; the yolk is reduced to $\leq 20 \%$ of the total egg mass, which now appears whitish. Spawning dates, brooding period, and time interval (interlude) between broods were determined from the successive appearance of these breeding activities. The spawning date was set for individuals carrying eggs of development stage $\mathrm{I}(\mathrm{a})$. A 1-day interval was observed between stages $I(a)$ and $I(b)$, and females carrying eggs of stage $\mathrm{I}(\mathrm{b})$ or later had their spawning date backdated accordingly. All females of any one sample carried eggs of the same development stage.

Monthly means of numbers of individual crabs and gonadosomatic and hepatosomatic indexes were calculated. These were analyzed using Spearman's correlation coefficients and $t$-tests (SYSTAT). 


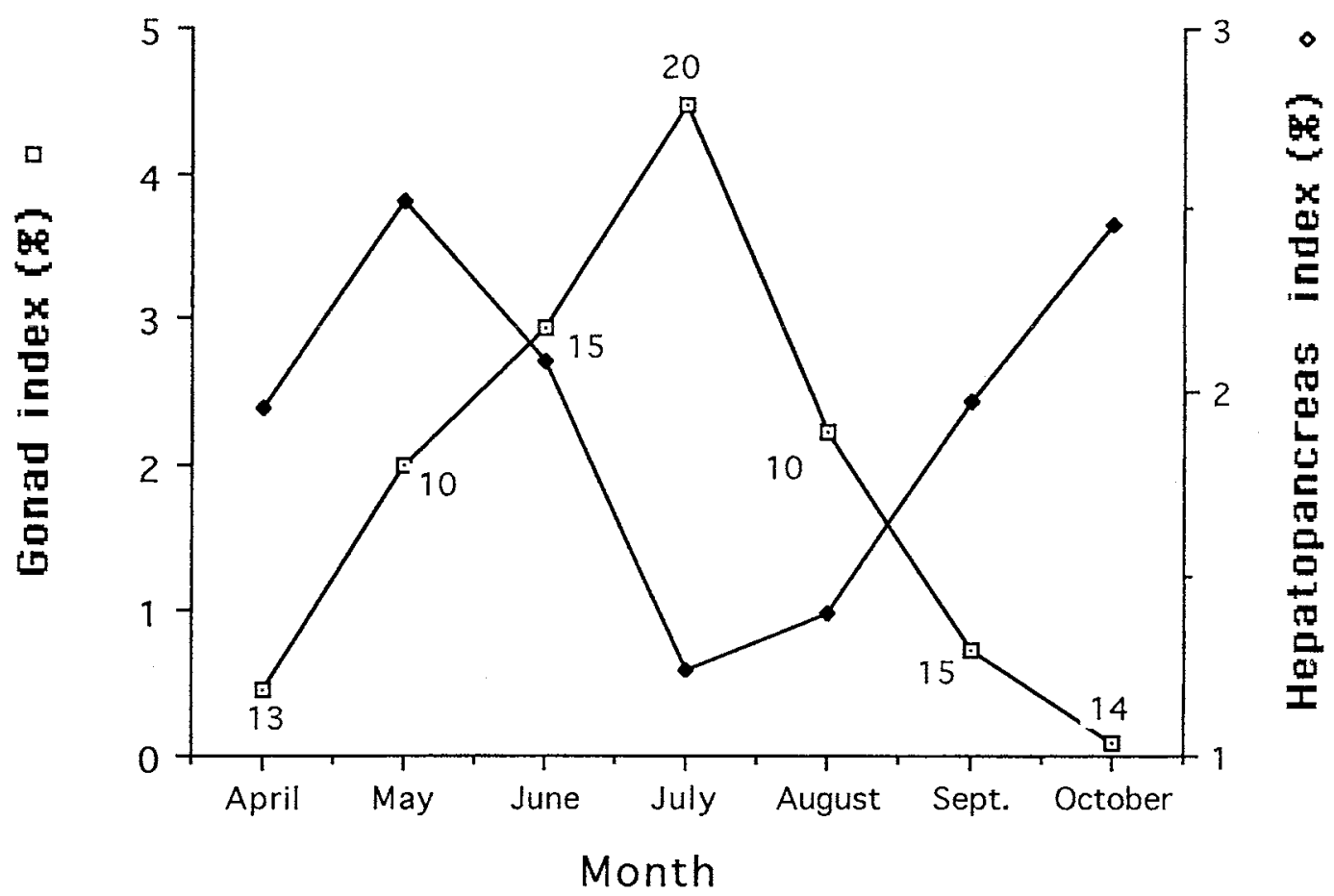

FrgURE 1. The inverse relationship of the female gonadosomatic and hepatosomatic indexes of Pilumnus vespertilio during the reproductive period. Numbers next to data points indicate female sample size from which the mean index was determined.

\section{RESULTS}

\section{Relationship between the Gonadosomatic Index and the Hepatosomatic Index}

The gonadosomatic index (GSI) started at a low level of $0.5 \%$ in April before reproduction started, with the hepatosomatic index (HSI) about three times higher. As the reproductive period started in May, there was a sharp rise of the GSI and this continued to a very significant $(t=4.87, P<0.001)$ high peak in July. The HSI increased, though not significantly $(t=1.36, P>0.05$ ), from April to May and then started decreasing steadily to a significantly $(t=4.56, P<0.05)$ lower level in July. There was a direct relationship between the declining of the HSI from May $(2.5 \%)$ to the July minimum $(1.2 \%)$ and the increase of the GSI from its lowest level $(0.5 \%)$ in April to the July maximum (4.5\%). Between July and October the HSI again increased steadily and significantly $(t=4.43$,
$P<0.05)$ while the GSI decreased significantly $(t=9.08, P<0.001)$ to levels of 2.4 and $0.1 \%$, respectively (Figure 1 ).

\section{Coupling and Ovigerous Females Related to Lunar Cycle}

Coupling was observed mostly around full moon, and the highest peak occurred 4 days after the full moon of every month in May, June, and July. In August, the peak occurred on the sixth day after the July full moon. The only two copulating pairs in September occurred 7 days after full moon (Figure 2). The coupling frequency increased from May and peaked in July. During that period, peaking times were shorter than from August to September when coupling was also decreasing. Although the number of active individuals fluctuated from day to day, it was slightly greater on the peak copulating days than on other days of every month except July. Sep- 


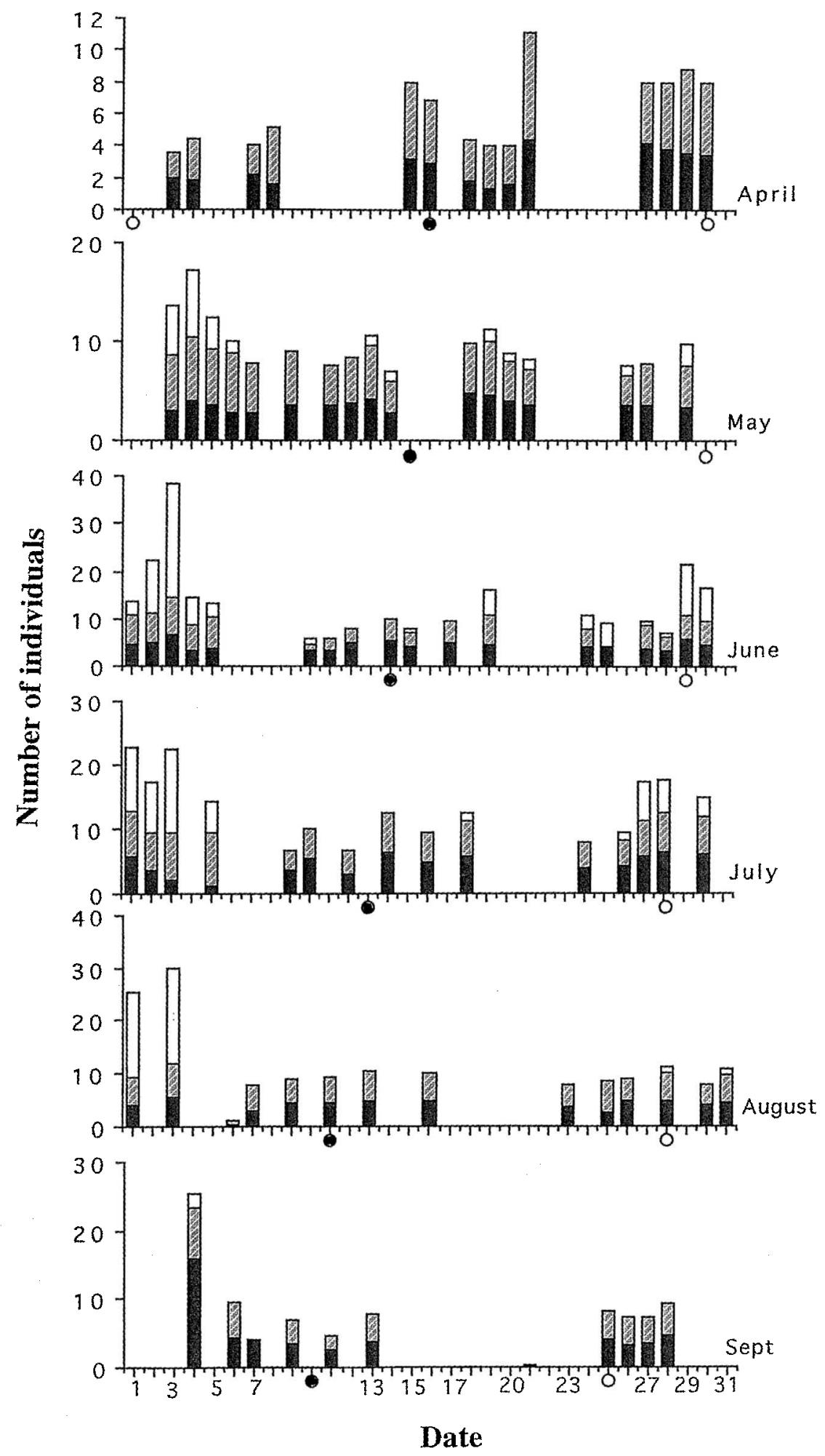

FIGURE 2. Temporal occurrence and distribution of number of copulating pairs (open bars), males (hatched bars), and females (solid bars) of Pilumnus vespertilio ( new moon; $\bigcirc$, full moon). 
tember had the least number of copulating pairs $(n=2)$ compared with May $(n=23)$, June $(n=82)$, July $(n=52)$, and August $(n=34)$. Although the number of copulating pairs in May was not significantly different $(t=0.532, P>0.05)$ from that in August, this number was significantly $(P<0.05)$ lower than that of June and July. There was no significant difference $(P>0.05)$ in the number of copulating pairs in June, July, and August.

Figure 3 shows that practically no ovigerous females could be seen between full moon and 5-10 days after full moon of each month. The interlude between brooding periods was $8.5 \pm 2.4$ days. For copulating pairs, the average number of daily active ovigerous females increased steadily from 11 in May, to 28 in June, to 45 in July, and began decreasing to 32 in August and 16 in September. Of the daily active number of mature females during the brooding period of each month, nearly $100 \%$ were ovigerous in July and August (Figure 3). The total number of ovigerous females in May and September was significantly $(P<0.05)$ smaller than the total number in either June, July, or August. However, there was no significant difference $(P>0.05)$ in the number of ovigerous females in June, July, and August.

\section{Spawning and Brooding Period Related to Lunar Cycle}

Females of $P$. vespertilio started spawning on 11 May, about 8 days after the first mating and copulating date on 3 May. This first spawn of May was brooded for 21 days, and all ovigerous females released their larvae 1 day before full moon. The incubation periods were 23, 21, 20, and 21 days in June, July, August, and September, respectively, and the larvae releasing events took place $2-3$ days before the day of the full moon. This gives an average incubation period of 21.2 days in $P$. vespertilio (Table 1). The incubation period between months was not significantly different. However, embryonic development stages were incubated for different lengths of time (days) and the number of developing days in advanced stages decreased in all months (Table 1). The embryonic development of stage I took the longest time (6.2 days) to develop to stage II, whereas stage $I V$ had the shortest duration (only 4 days to develop to larval stage and release time). The number of developmental days between stage I and II was not significantly different $(t=1.00, P>0.05)$. However, other comparisons of development stages were significantly different: between stage I and III $(t=5.19, P<0.05)$, stage I and IV $(t=8.66, P<0.05)$, stage II and III $(t=5.00, P<0.05)$, stage II and IV $(t=9.00, P<0.05)$, and between stage III and $\mathrm{IV}(t=6.00, P<0.05)$.

\section{Air and Pool Water Temperatures Versus Brooding}

Both air and pool water temperatures increased from the lowest $\left(26.7^{\circ} \mathrm{C}\right.$ and $25.5^{\circ} \mathrm{C}$ ) in April to the highest $\left(31.6^{\circ} \mathrm{C}\right.$ and $\left.33.7^{\circ} \mathrm{C}\right)$ in July, respectively (Table 2). Variations in air and pool water temperatures occurred between months. These variations were either significantly different (e.g., between May and June [air (A), $t=4.429, P<0.05$; pool water (PW), $t=6.804, P<0.05])$ or not significantly different (e.g., between June and July [A, $t=1.247, P>0.05 ;$ PW, $t=1.275$, $P>0.05])$. Temperature seemed not to have any influence on the variations of embryonic development stages and on the duration of brooding period between months (Table 2). For example, females in June, which had pool water temperature equally as high as in $\mathrm{Au}-$ gust but relatively lower than in July, incubated eggs for the longest period (23 days).

\section{DISCUSSION}

A high hepatosomatic index at the beginning of the reproductive period was followed by a high gonadosomatic index and therefore a large number of ovigerous females. In this and other cited studies, the hepatosomatic index declines and always stays at lower levels during the reproductive period when organic sources are being mobilized for vitellogenesis (Kyomo 1986, 1988, Omori et al. 1997, Tsuchida and Watanabe 1997). Most probably, food acquisition (i.e., feeding) does not compensate for the organic materials utilized 


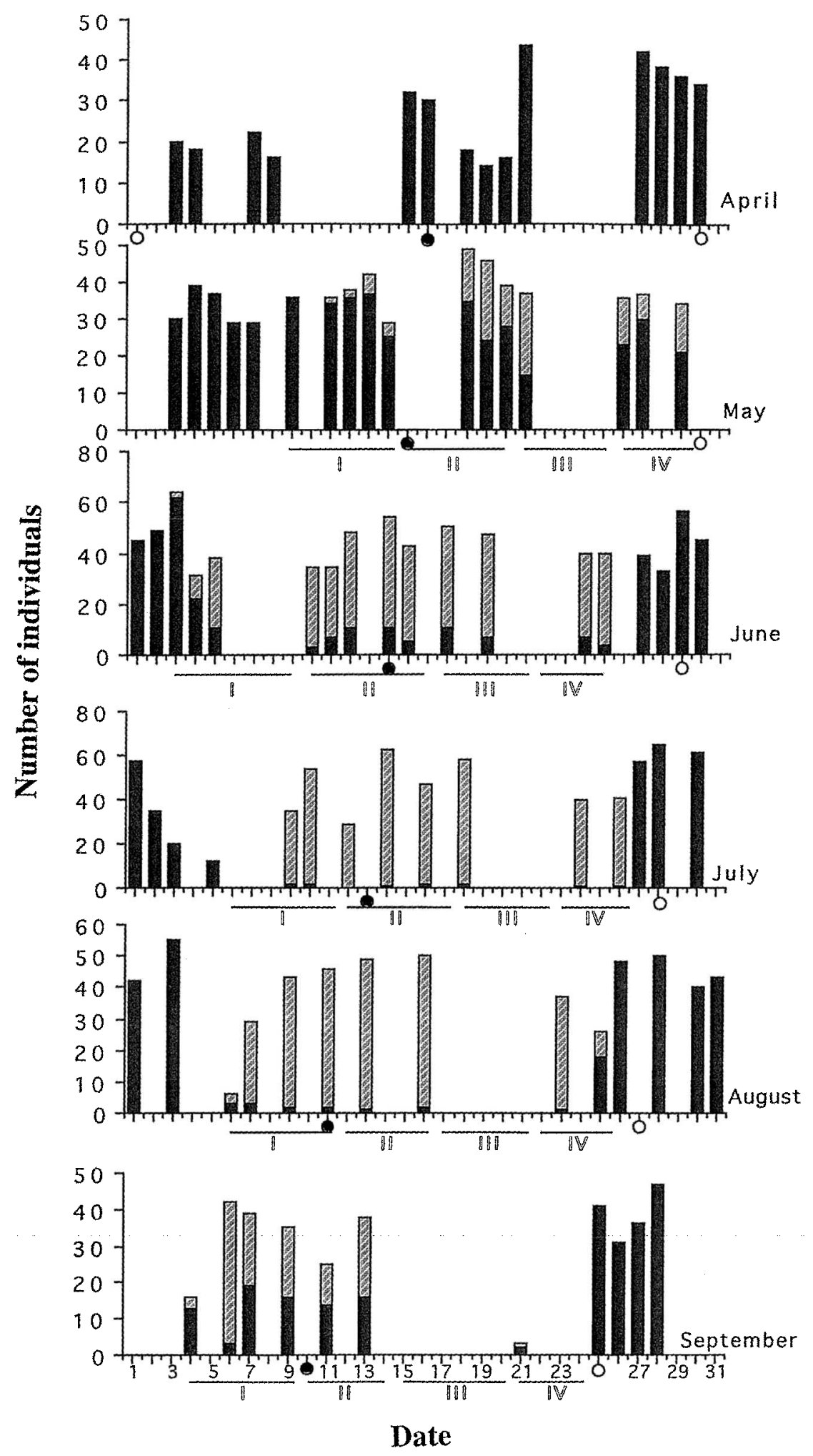

FIgURE 3. Occurrence and distribution of number of ovigerous females (hatched bars) and mature nonovigerous females (solid bars) in relation to the lunar cycle (new and full moon as in Figure 2). Bars and roman numerals below the dates for each month indicate brooding periods and embryonic development stages, respectively. 
TABLE 1

Number of Days of Development of Embryonic Stages of Pilumnus vespertilio in Each Month

\begin{tabular}{llllllll}
\hline & \multicolumn{7}{c}{ Month } \\
\cline { 2 - 7 } Stage & May & June & July & August & September & October & Mean \\
\hline I & $6(6)$ & $7(13)$ & $6(38)$ & $6(29)$ & $6(20)$ & $6(3)$ & 6.2 \\
II & $6(18)$ & $7(36)$ & $6(54)$ & $5(50)$ & $5(17)$ & - & 5.8 \\
III & $5(17)$ & $5(39)$ & $5(56)$ & $5(-)$ & $6(-)$ & - & 5.2 \\
IV & $4(11)$ & $4(19)$ & $4(40)$ & $4(22)$ & $4(-)$ & - & 4 \\
Total (days) & 21 & 23 & 21 & 20 & 21 & - & 21.2 \\
Mean number of days of development per stage \\
\hline
\end{tabular}

Note: Mean number of active ovigerous females of each embryonic development stage is shown in parentheses. Only two ovigerous females with stage IV eggs were active on 21 September following a strong typhoon, and only three females became ovigerous in October (see Figure 3). October females are not included in the determination of the mean.

TABLE 2

Monthly Air (A) and Pool Water (PW) Temperatures $\left({ }^{\circ} \mathrm{C}\right)($ Mean \pm SD) during the Observed Spawning and Brooding Periods at the Bise Study Site

\begin{tabular}{|c|c|c|c|c|c|c|c|c|}
\hline & \multicolumn{8}{|c|}{ Monthly Temperatures $\left({ }^{\circ} \mathrm{C}\right)$} \\
\hline & \multicolumn{2}{|c|}{ April } & \multicolumn{2}{|c|}{ May } & \multicolumn{2}{|c|}{ June } & \multicolumn{2}{|c|}{ July } \\
\hline & $\mathrm{A}$ & PW & A & PW & A & PW & $\mathrm{A}$ & PW \\
\hline \multirow[t]{3}{*}{$\begin{array}{l}\text { Range } \\
\text { Mean }\end{array}$} & $\begin{array}{c}25-28 \\
26.7 \pm 1.3\end{array}$ & $\begin{array}{c}24-27 \\
25.5 \pm 0.9\end{array}$ & $\begin{array}{c}23-31 \\
26.5 \pm 2.3\end{array}$ & $\begin{array}{c}25-32 \\
27.0 \pm 2.3\end{array}$ & $\begin{array}{c}29-33 \\
30.5 \pm 1.2\end{array}$ & $\begin{array}{c}29-35 \\
31.6 \pm 2.2\end{array}$ & $\begin{array}{c}30-34 \\
31.6 \pm 1.3\end{array}$ & $\begin{array}{c}30-36 \\
33.7 \pm 1.9\end{array}$ \\
\hline & \multicolumn{2}{|c|}{ August } & \multicolumn{2}{|c|}{ September } & & & & \\
\hline & $\mathrm{A}$ & PW & A & $\mathrm{PW}$ & & & & \\
\hline $\begin{array}{l}\text { Range } \\
\text { Mean }\end{array}$ & $\begin{array}{c}30-33 \\
31.7 \pm 1.3\end{array}$ & $\begin{array}{c}30-34 \\
31.5 \pm 1.6\end{array}$ & $\begin{array}{c}29-32 \\
30.9 \pm 1.5\end{array}$ & $\begin{array}{c}30-35 \\
31.0 \pm 1.5\end{array}$ & & & & \\
\hline
\end{tabular}

Note: Data were collected on only 10 days in October and therefore its mean temperatures were not included.

from the hepatopancreas at a rate fast enough to meet the reproductive activities (Kyomo 1988, 1999). When the breeding period ends, there is a rise in the index level of the hepatopancreas because more organic materials are stored again and ready for the beginning of the next reproductive period. This shows that the hepatopancreas plays a vital role in the breeding periodicity of crabs. The gonadosomatic index, a more important indicative parameter for breeding periodicity, depends very much on the organic materials stored in the hepatopancreas. This index is high when the hepatosomatic index is low, and vice versa.

At a local population level, environmental physical factors such as temperature may control and trigger the activity and timing of reproduction in crabs (Sastry 1983, Kyomo 1986). However, in some cases such factors may not be more important for continuous breeding periods than food availability can be (e.g., Kyomo 1986, Henmi and Kaneto 1989, Emmerson 1994). If food is considered a more important factor than the physical environment for the initialization of reproduc- 
tive activities, feeding activity has neither a direct and immediate effect on vitellogenesis nor on the breeding periodicity than the stored material in the hepatopancreas (Adiyodi 1969, Kyomo 1988).

The mating, copulation, and egg-bearing times in $P$. vespertilio are strategically separated in time according to the lunar cycle. The highest number of copulating pairs occurred soon after full moon. Copulating after the full moon leaves the female 20 to 23 days to spawn and brood the eggs for the required period, allowing release of larvae on a day synchronized with a high tide of the next full moon. The lunar rhythmicity in the mating activity of crabs has been reported in various works (e.g., Christy 1978, Greenspan 1982, and Kosuge et al. 1994). In many other crab species (Adiyodi 1969, Kyomo 1988, Omori et al. 1997), a remarkable role of the hepatopancreas has been shown in the breeding activity of $P$. vespertilio. Ovigerous females of $P$. vespertilio appear a few days after full moon and release larvae (end the brooding time) before the next full moon. Apparently, it is only during this time that larvae can be released if reproduction is to be a success. No ovigerous females were observed on or a few days after the full moon each month.

Most likely the breeding period in $P$. vespertilio is 5 months, and its beginning seems to differ by weeks from year to year according to the moon calendar. In this study the period was observed to be from mid-May to September. However, ovigerous females were observed on 24 April in 1998, when the active period started in March (pers. obs.). But the breeding period that year ended in September (unpubl. data), similar to findings in this study. Watanabe et al. (1990) reported the breeding period of xanthid crab Leptodius exaratus distributed in the same latitudinal range to be from mid-May to September. $P i-$ lumnus vespertilio and L. exaratus seem to exhibit slightly different life histories, probably due to the fact that the former species experiences more tropical conditions than the temperate ones that are experienced by the latter species. Although the number of broods per individual female per season was not es- tablished, most brachyurans are able to spawn more than once in a single breeding period (e.g., Wada 1981, Kyomo 1986, Tsuchida and Watanabe 1997), and $P$. vespertilio probably behaves similarly.

Variations in the duration of the reproductive season among major genera of xanthids (of which $P$. vespertilio was a member [Kyomo 1999, 2001]) are common. Lophopanopeus bellus bellus breeds for 10 months (Knudsen 1964), L. l. leucomanus and L. bellus diegensis for 9 months, Paraxantbias taylori for 6 months, and Cycloxantbops novemdentatus for only 3 months (Knudsen 1960). Others, such as Neopanope sayi, breed for 6 months (Swartz 1978), Eurypanopeus depressus and Panopeus berbstii for 8 months (McDonald 1982), and Eriphia smithii for 4 months (Tomikawa and Watanabe 1992). These variations are probably due to a latitudinal difference: species closer to low latitudes such as L. bellus bellus (Knudsen 1964) tend to have continuous breeding periods. Pilumnus species with abbreviated development, however, incubate eggs between 2 to 4 months (Wear 1967). The duration of egg brooding in $P$. vespertilio is 21.2 days with a resting period of 5-10 days between broods. The incubation periods observed in (other) xanthids were 25 days for Lophopanopeus bellus bellus (Knudsen 1960) and 21 days for $L$. exaratus (Watanabe et al. 1990).

In most temperate and probably all poikilothermic invertebrates, ambient temperature seems to be the most important external factor controlling the duration of embryonic development (Swartz 1978, Kyomo 1986). This factor seems not to be important for the subtropical $P$. vespertilio (Tables 1 and 2). The periodicity of the moon is a stronger factor in control of embryonic development in $P$. vespertilio than the temperature factor.

\section{CONCLUSIONS}

For many marine brachyurans, and probably for other species of marine organisms, breeding periodicity is synchronized with environmental cycles such as phase of the moon (e.g., Forward et al. 1982). Most intertidal animals 
release their larvae during high tides of the full moon (Forward et al. 1982, Christy 1986). But lunar periodicity in hatching of brachyurans is just one and the last event of the egg-carrying period. Data in this study support the thesis that copulation, spawning, and incubation periods in $P$. vespertilio are also synchronized with the lunar cycle so that each episode leads to the production of offspring during appropriate hatching conditions: high tide. This breeding period in $P$. vespertilio seems to be synchronized within individuals too because all reproducing females in successive broods become more or less ovigerous on the same day, even when taken from separate populations. Furthermore, $100 \%$ of ovigerous females of any one sample and time carry eggs in the same development stage. This synchrony indicates that some kind of an endogenous control mechanism is present in all individuals. This mechanism has also been implicated in controlling the breeding cycle of Neopanope sayi as observed in the laboratory (De Vries and Forward 1989). The mechanism most likely also triggers all reproductively active females of $P$. vespertilio to attract copulating partners and start spawning on a day that will allow the brooding time to end at the beginning of the next full moon of the lunar cycle.

Ultimately it is the larvae that must be produced during the appropriate time if the population of a particular species is to grow and avoid death in the environmentally adverse conditions of the intertidal habitats. There are evolutionary advantages for the larvae to be released according to the lunar cycle and during high tide. These include allowing increased dispersal from the parent population to avoid competition for food (Christy 1978, Saigusa 1981) and allowing larvae to be carried to deep water, decreasing predation by planktivorous animals and minimizing mortality from adverse changes in conditions such as temperature and salinity in shallow water. For a species with low population density, cyclical reproduction must be accompanied by a high rate of oviposition (Omori et al. 1997). Most of these results and arguments for other species seem to be applicable in describing the life cycle of $P$. vespertilio in this study. A breeding period synchronized with the lunar cycle at both the individual and population levels has been shown in $P$. vespertilio, the only pilumnid crab studied in such detail so far.

\section{ACKNOWLEDGMENTS}

I thank M. Murai of the Tropical Biological Research Center, Sesoko, for reading the initial version of the manuscript and the anonymous reviewers for their valuable comments that greatly improved the manuscript.

\section{Literature Cited}

Adiyodi, R. T. 1969. On the storage and mobilization of organic resources in the hepatopancreas of a crab Paratelpbusa bydrodromus. Experientia (Basel) 25:43-44.

Archambault, J. A., E. L.Wenner, and J. D. Whitaker. 1990. Life history and abundance of blue crab, Callinectes sapidus, at Charleston Harbour, South Carolina. Bull. Mar. Sci. 46:145-158.

Christy, J. H. 1978. Adaptive significance of reproductive cycles in the fiddler crab Uca pugilator: A hypothesis. Science (Washington, D.C.) 199:435-455.

- 1986. Timing of larval release by intertidal crabs on an exposed shore. Bull. Mar. Sci. 39:176-191.

De Vries, M. C., and R. B. Forward Jr. 1989. Rhythms in larval release of the sublittoral crab Neopanope sayi and the supralittoral crab Sesarma cenereum. Mar. Biol. (Berl.) 100:241-248.

Emmerson, W. D. 1994. Seasonal breeding cycles and sex ratios of eight species of crabs from Mgazana, a mangrove estuary in Transkei, southern Africa. J. Crustacean Biol. 14:568-578.

Forward, R. B., K. J. Lohmann Jr., and T. W. Cronin. 1982. Rhythms in larval release by an estuarine crab (Rbitbropanopeus barrisii). Biol. Bull. (Woods Hole) 163:287-300.

Giese, A. C., and J. S. Pearse. 1974. General principles. Pages 1-49 in A. C. Giese and J. S. Pearse, eds. Reproduction of marine invertebrates: Acoelomate and pseudocoe- 
lomate metazoans. Academic Press, New York.

Greenspan, B. N. 1982. Semi-monthly reproductive cycles in male and female fiddler crabs, Uca pugnax. Anim. Behav. 30:1084-1092.

Greenwood, J. G., and D. R. Fielder. 1988. Larval development of three species of Sesarma (Crustacea, Brachyura, Grapsidae) from eastern Australia. Micronesica 21:5567.

Henmi, Y., and M. Kaneto. 1989. Reproductive ecology of 3 ocypodid crabs. I. The influence of activity differences on reproductive traits. Ecol. Res. 4:17-29.

Hiatt, R. W. 1948. The biology of the lined shore crab, Pacbygrapsus crassipes Randall. Pac. Sci. 2:135-213.

Knudsen, J. W. 1960. Reproduction, life history and larval ecology of the California Xanthidae, the pebble crabs. Pac. Sci. $14: 3-17$.

- 1964. Observations of the reproductive cycles and ecology of the common Brachyura and crab-like Anomura of Puget Sound, Washington. Pac. Sci. 18:3-33.

Kosuge, T., M. Murai, and S. Poovachiranon. 1994. Breeding cycle and mating behaviour of the tropical ocypodid Ilyoplax gangentica. Trop. Zool. 7:25-34.

Kyomo, J. 1986. Reproductive activities in the sesarmid crab Sesarma intermedia in the coastal and estuarine habitats of Hakata, Japan. Mar. Biol. (Berl.) 91:319-329.

. 1988. Analysis of the relationship between gonads and hepatopancreas in males and females of the crab Sesarma intermedia with reference to resource use and reproduction. Mar. Biol. (Berl.) 97:87-93.

- 1999 . Feeding patterns, habits and food storage in Pilumnus vespertilio (Brachyura: Xanthidae). Bull. Mar. Sci. 65:381389.

2001. Reproductive behaviour of the play-dead hairy Pilumnus vespertilio (Crustacea: Brachyura: Pilumnidae) with respect to carapace size. Bull. Mar. Sci. 68:37-46.

Lim, S. S. L., and W. H. Tan. 1981. Larval development of the hairy crab, Pilumnus vespertilio (Fabricius) in the laboratory and comparisons with larvae of Pilumnus dasy- podus Kingsley and $P$. sayi Rathbun. Crustaceana (Leiden) 41:71-88.

McDonald, J. 1982. Divergent life history patterns in the co-occurring intertidal crabs Panopeus berbstii and Eurypanopeus depressus. Mar. Ecol. Prog. Ser. 8:173-180.

Norman, C. P. 1996. Reproductive biology and evidence for hard-female mating in the brachyuran crab Thalamita sima (Portunidae). J. Crustacean Biol. 16:656-662.

Norman, C. P., and M. B. Jones. 1993. Reproductive ecology of the velvet swimming crab, Necora puber, at Plymouth. J. Mar. Biol. Assoc. U.K. 73:379-389.

Omori, K., K. Shiraishi, and M. Hara. 1997. Life histories of sympatric mud-flat crabs, Helice japonica and $H$. tridens, in a Japanese estuary. J. Crustacean Biol. 17:279288.

Saigusa, M. 1981. Adaptive significance of semilunar rhythm in the terrestrial crab Sesarma. Biol. Bull. (Woods Hole) 160: 311-321.

Sakai, T. 1976. Crabs of Japan and the adjacent seas. Kodansha, Tokyo.

Sastry, A. N. 1983. Ecological aspects of reproduction. Pages 179-270 in F. J. Vernberg and W. B. Vernberg, eds. The biology of Crustacea. Vol. 8. Environmental adaptations. Academic Press, New York.

Seiple, W. 1979. Distribution, habitat preferences and breeding periods in the crustaceans Sesarma cinereum and S. reticulatum. Mar. Biol. (Berl.) 52:77-86.

Swartz, R. C. 1978. Reproductive and moult cycles in the xanthid crab Neopanope sayi. Crustaceana (Leiden) 34:15-32.

Tomikawa, N., and S. Watanabe. 1992. Reproductive ecology of the xanthid crab Eripbia smitbii. J. Crustacean Biol. 12:5767.

Tsuchida, S., and S. Watanabe. 1991. Growth and reproduction of the spider crab, Tiarinia cornigera. Researches on Crustacea No. 20. Carcinological Society of Japan, Tokyo.

. 1997. Growth and reproduction of the grapsid crab Plagusia dentipes. J. Crustacean Biol. 17:90-97.

Wada, K. 1981. Growth, breeding and re- 
cruitment in Scopimera globosa and Ilyoplax pusillus, in the estuary of Waka River, middle Japan. Publ. Seto Mar. Biol. Lab. 26:243-259.

Watanabe, S., H. Yamana, and N. Tomokawa. 1990. Reproduction of the xanthid crab Leptodius exaratus. Researches on Crustacea No. 19. Carcinological Society of Japan, Tokyo.
Wear, G. R. 1967. Life history studies on New Zealand Brachyura. 1. Embryonic and post embryonic development of $\mathrm{Pi}$ lumnus novaezealandiae and $P$. lumpinus. $\mathrm{N}$. Z. J. Mar. Freshwater Res. 1:482-535.

Zucker, N. 1978. Monthly reproductive cycles in 3 sympatric hood-building tropical fiddler crabs (genus $U c a$ ). Biol. Bull. (Woods Hole) 155:410-424. 